Research paper

\title{
Risk factors for acquiring varicella zoster virus (VZV) infection, and sero-prevalence of anti-VZV immunoglobulin $G$ antibodies in adolescents from a tropical population
}

\author{
F Noordeen $^{1 *}$, R Dissanayake $^{1}$, IKB Weerasekara ${ }^{1}$, PVR Kumarasiri $^{2}$, MH Wijedasa ${ }^{1}$ \\ Sri Lankan Journal of Infectious Diseases 2014 Vol.4 (1):30-37 \\ DOI: http://dx.doi.org/10.4038/sljid.v4i1.5852
}

Key words: Varicella, adolescents, sero-prevalence, Sri Lanka, tropical countries.

\begin{abstract}
Introduction: Little is known about the sero-prevalence of anti-VZV antibodies among adolescents in the Kandy district of Sri Lanka although adulthood VZV infections are very common in this part of the country.

Design: Socio-demographic data and blood samples were collected between November 2004 and April 2005 from a total of 271, 12 to 19 year old school students from urban, rural and estate communities. Sera were tested for anti-VZV IgG antibodies using a standard enzyme-linked immunosorbent assay.

Results: Sero-prevalence of anti-VZV antibodies among these adolescents was found to be $34 \%$. Number of siblings (39\% of adolescents with more than 2 siblings and $27 \%$ of those with 2 siblings were immune, while those without siblings were non-immune) and areas of residence (urban, estate and rural) were statistically associated with the presence of anti-VZV IgG antibodies. School children who lived in the urban and estate sectors had significantly higher anti-VZV IgG prevalence rates than those who lived in rural areas $(p<0.001)$.
\end{abstract}

Conclusions: Sero-prevalence of anti-VZV IgG antibodies was low among adolescents in the Kandy district. Adolescents who lived in the urban areas had a significantly higher rate of anti-VZV IgG antibodies than those who lived in rural areas $(p<0.001)$. Adolescents who grow up without siblings are at risk of evading the childhood VZV infection and form a potential target group for adulthood chickenpox.

\section{Introduction}

Primary infection with varicella-zoster virus (VZV) causes varicella (chickenpox) which is a common childhood exanthematous illness associated with fever and a

\footnotetext{
${ }^{1}$ Department of Microbiology, Faculty of Medicine, University of Peradeniya, Sri Lanka

${ }^{2}$ Department of Community Medicine, Faculty of Medicine, University of Peradeniya, Sri Lanka
}

Address for correspondence: Dr F Noordeen, Department of Microbiology,

Faculty of Medicine, University of Peradeniya, Sri Lanka

E-mail: faseeha.noordeen12@gmail.com; faseehan@pdn.ac.lk; Tel.no:+94812396532 
generalized pruritic vesicular eruption. ${ }^{1}$ Reactivation of dormant VZV causes herpes zoster (shingles) which is characterised by a localised painful vesicular eruption involving one or more adjacent dermatomes. ${ }^{1,2}$ The incidence of herpes zoster increases with age and compromised immunity due to illness or medical treatment. ${ }^{2}$

Chickenpox often presents clinically as a highly contagious benign viral infection of children throughout the world. ${ }^{1}$ In adults, the clinical severity of the disease is high and in the immuno-compromised and elderly it can be fatal, with mortality rates reaching up to $15 \% .{ }^{3}$ Complications of chickenpox during the first two trimesters of pregnancy may result in chickenpox embryopathy, congenital varicella syndrome and premature labour. ${ }^{2}$ In the last trimester it may result in neonatal varicella, which if severe may reach a mortality rate of $30 \%$. $^{4}$

VZV is spread by direct contact with the infected lesions of patients with chickenpox or zoster. Transmission occurs by inhalation of respiratory secretions of infected patients, and contact with articles contaminated with vesicular fluid. ${ }^{1} \mathrm{VZV}$ is highly infectious, with an attack rate of $80 \%$ in household settings in urban communities. ${ }^{2}$ Acquired immunity develops following natural infection, which protects the exposed individuals from subsequent infection. However, re-infections are possible in immunocompromised patients. ${ }^{1-3}$

In most temperate climates, VZV infection is more common in the winter and early spring and in these countries up to 90 to $95 \%$ of the adult population have serological evidence of past exposure to the virus. ${ }^{5}$ A randomly selected Turkish population had $90 \%$ sero-positivity to anti-VZV IgG when the subjects were under the age of 30 . Moreover, a sero-prevalence study conducted in an adolescent population in Switzerland showed a positive anti-VZV IgG antibody rate of $>95 \%$. In contrast, in countries experiencing a tropical climate, up to $60 \%$ of the population remain susceptible to VZV infection into adulthood. In India an overall sero-prevalence of $68 \%$ was noted for anti-VZV IgG antibodies in 1609 patients aged from 0 to 40 years, with a significant proportion of adolescents and adults being susceptible to VZV. ${ }^{6}$ Lower herd immunity and higher susceptibility of the young adult population to VZV have also been observed in Singapore ${ }^{7}$ and Pakistan. ${ }^{8}$

To date, published data on sero-prevalence of anti-VZV IgG antibodies in the adolescent population of Sri Lanka is limited. A study conducted by Liyanage et al. $(2007)^{9}$ showed that young adults in the Colombo (capital of Sri Lanka) district have a very low sero-positivity rate to anti-VZV IgG. By the age of 20, sero-positivity rates as demonstrated by VZV IgG antibodies, in urban and rural areas were $\sim 40 \%$ and $20 \%$, respectively. ${ }^{9}$ In Saudi Arabia, 35\% Sri Lankans living in the region are at higher risk for adulthood chickenpox than the native Saudi population. ${ }^{10}$ It has also been reported that a significant number of undergraduate students experience chickenpox every year in a leading university in the Kandy district of Sri Lanka (Personal communication). This was supported by a recent study in which $50.9 \%(222 / 436)$ of the medical and engineering undergraduate students (Age $=19-21$ years) were susceptible to VZV infection. ${ }^{11}$ This study might have underestimated the true susceptibility rate to VZV in 
their study population as it only tested those with a negative history of chickenpox for anti-VZV IgG antibodies.

\section{Objectives}

The objective of this project was to study the risk factors for adulthood chickenpox in a vaccine-naive adolescent population of school children from urban, rural and estate communities of the Kandy district of Sri Lanka and determine the sero-prevalence of anti-VZV IgG antibodies in this population.

\section{Methodology}

The study was approved by the Ethics Committee of the Faculty of Medicine, University of Peradeniya, Sri Lanka.

A cross sectional study was carried out between November 2004 and April 2005 in adolescent school children of urban, rural and estate communities in the Kandy District of Sri Lanka (chosen using the Department of Education Registry of the Kandy district) to determine the sero-prevalence of anti-VZV IgG antibodies and assess the risk factors for adulthood chickenpox. A sample size of 271 participants was made based on a multi stage stratified random sampling formula for health studies to achieve a power of 0.85 and confidence interval (CI) of $95 \% .^{12}$

Informed written consent was obtained from all participants, parents or guardians. A pre-tested questionnaire was completed by the researchers to collect the added information from the participants. The questionnaire included demographic information, past history of chickenpox, number of siblings and chickenpox vaccination history or record. Approximately, $5 \mathrm{~mL}$ of venous blood was taken from the median cubital vein of all the subjects participating in the study.

Blood samples were transported to the Virology Laboratory of the Department of Microbiology, Faculty of Medicine, University of Peradeniya for serum separation and storage at $-20^{\circ} \mathrm{C}$ until tested. All serum samples were tested for the presence of antiVZV IgG antibodies using a commercial ELISA (Enzygnost, Behring Diagnostics, Germany). Positive results were obtained using a fixed cut-off recommended by the manufacturer. This test has a specificity of $100 \%$ and a sensitivity of $93 \%$ according to the manufacturer. Results were analysed using SPSS statistical software for Windows, Version 12.0.

\section{Results}

The current study showed a low sero-prevalence of anti-VZV IgG antibodies among the adolescent population of the Kandy district of Sri Lanka. None of the students were vaccinated against chickenpox. Overall, $34 \%$ of the participating students tested were sero-positive to anti-VZV IgG antibodies (or immune to chickenpox). Students with no history of chickenpox and students who could not remember having chickenpox had $32 \%$ and $14 \%$ of sero-positivity to anti-VZV IgG antibodies, respectively. Students 
who could remember a past history of chickenpox and those informed by their parents about a past history of chickenpox had $53 \%$ and $33 \%$ of sero-prevalence to anti-VZV IgG antibodies, respectively (Table 1).

Table 1: Sero-prevalence of anti-VZV IgG antibodies $v$ s past history of chickenpox among an adolescent population of the Kandy district of Sri Lanka

\begin{tabular}{|c|c|c|c|}
\hline Past history of chickenpox & $\%$ Immune & \% Non immune & Total \\
\hline No past history of chickenpox & $32.4^{\mathrm{a}}(22)^{\mathrm{b}}$ & $67.6^{\mathrm{a}}(46)^{\mathrm{b}}$ & $100^{\mathrm{a}}(68)^{\mathrm{b}}$ \\
\hline I can't remember & $14.4^{\mathrm{a}}(13)^{\mathrm{b}}$ & $85.6^{\mathrm{a}}(77)^{\mathrm{b}}$ & $100^{\mathrm{a}}(90)^{\mathrm{b}}$ \\
\hline I know from my parents & $33.3^{\mathrm{a}}(5)^{\mathrm{b}}$ & $66.7^{\mathrm{a}}(10)^{\mathrm{b}}$ & $100^{\mathrm{a}}(15)^{\mathrm{b}}$ \\
\hline I can remember & $53.1^{\mathrm{a}}(52)^{\mathrm{b}}$ & $46.9^{\mathrm{a}}(46)^{\mathrm{b}}$ & $100^{\mathrm{a}}(98)^{\mathrm{b}}$ \\
\hline Total & $33.9^{\mathrm{a}}(92)^{\mathrm{b}}$ & $66.1^{a}(179)^{b}$ & $100^{\mathrm{a}}(271)^{\mathrm{b}}$ \\
\hline
\end{tabular}

Male and female students had approximately $36 \%$ and $32 \%$ sero-prevalence rates respectively for anti-VZV antibodies The difference in the sero-prevalence rate between the genders was not statistically significant $(P>0.05)$.

Taking into consideration the number of siblings, students without sibling/s or who had only one sibling were non-immune (0/20), those who had 2 siblings and those who had more than 2 siblings had 27\% (17/62) and 39\% (74/189) sero-positivity to anti-VZV IgG antibodies, respectively. An increase in sero-positivity to anti-VZV IgG antibodies was noted with an increase in the number of siblings. The difference in sero-prevalence rate between students with 2 or more siblings and students without siblings was statistically significant $(P<0.001)$. The source of infection of chickenpox was unknown to many students although a few students reported contact with a relative or a friend having chickenpox.

Students from the urban and estate communities had approximately 53\% and 31\% seroprevalence rates to anti-VZV IgG antibodies respectively. Only $17 \%$ of the students from the rural community were positive for anti-VZV IgG antibodies (Table 2).

Table 2: Sero-prevalence of anti-VZV IgG antibodies among adolescents in rural, estate and urban communities of the Kandy district of Sri Lanka

\begin{tabular}{llll}
\hline Communities & Immune \% & Non immune\% & Total \\
\hline Rural & $17.4^{\mathrm{a}}(16)^{\mathrm{b}}$ & $82.6^{\mathrm{a}}(76)^{\mathrm{b}}$ & $100^{\mathrm{a}}(92)^{\mathrm{b}}$ \\
Estate & $31.1^{\mathrm{a}}(28)^{\mathrm{b}}$ & $68.9^{\mathrm{a}}(62)^{\mathrm{b}}$ & $100^{\mathrm{a}}(90)^{\mathrm{b}}$ \\
Urban & $53.3^{\mathrm{a}}(48)^{\mathrm{b}}$ & $46.7^{\mathrm{a}}(41)^{\mathrm{b}}$ & $100^{\mathrm{a}}(89)^{\mathrm{b}}$ \\
\hline Total & $\mathbf{3 3 . 8}^{\mathrm{a}}(\mathbf{9 2})^{\mathrm{b}}$ & $\mathbf{6 6 . 2}^{\mathrm{a}}(\mathbf{1 7 9})^{\mathrm{b}}$ & $\mathbf{1 0 0}^{\mathrm{a}}(\mathbf{2 7 1})^{\mathrm{b}}$ \\
\hline${ }^{\mathrm{a}}$ Percentage of adolescents $(\%)$ and & \\
\end{tabular}

Differences in the percentage of sero-positivity to anti-VZV IgG antibodies between different communities (urban $v s$ estate; urban $v s$ rural; estate $v s$ rural) were statistically significant $(P<0.001)$. 


\section{Discussion}

An overall sero-prevalence of $34 \%$ to anti-VZV IgG antibodies among adolescents in the Kandy district of Sri Lanka produces a susceptibility rate of $66 \%$. These findings are in agreement with the findings of Liyanage et al. $(2007)^{9}$ in which an age cohort of 0-60 years in the Colombo district of Sri Lanka had an anti-VZV sero-prevalence of $38 \%$, producing a similar level of susceptibility to VZV infection. Taking together the findings of Liyanage et al. $(2007)^{9}$ and the current study, it is not surprising to see the level of hospital admissions, disease severity and complications with a high mortality rate for chickenpox in a central infectious disease hospital in Sri Lanka. ${ }^{13}$ There is evidence to support the increased disease severity of chickenpox with age, and peripheral blood viral loads were significantly higher in those aged over 20 years than those aged $<20$ years in a Sri Lankan cohort of patients with adulthood chickenpox. ${ }^{14}$

The low sero-prevalence of anti-VZV IgG antibodies in the present study was comparable to that reported in other tropical developing countries. Factors which influence low exposure rate to VZV in tropical developing countries are not well known. However, several reasons can be suggested, such as different virus strains, climatic factors, socio-economic standards, cultural factors and population mobility. According to a study carried out in a region of tropical Australia, 92\% exposure rate to VZV was noted in women attending an antenatal clinic. ${ }^{15}$ This finding may support the importance of socio-economic standards, cultural factors and population mobility over the climatic factor for the discrepancy in the exposure rate to VZV. A fact that cannot be disregarded is that most developed countries experience a temperate climate and developing countries experience a tropical climate. On the other hand, sero-prevalence rate of anti-VZV IgG antibodies was higher in cooler climatic regions than in the warmer regions of Thailand. ${ }^{16}$ The latter observation can be supported by the findings reported in a study carried out in Singapore. ${ }^{7}$ In this study, lower herd immunity and the higher susceptibility of the young adult population to VZV have been seen irrespective of the fact that Singapore has socio-economic standards comparable to a developed country.

Significantly, less numbers of adolescents who had no history of chickenpox (32\%) or cannot remember having the disease (14\%) were immune (Table 1). In contrast, in a Canadian study, $62 \%$ of those with "negative or unknown history" of chickenpox were sero-positive for anti-VZV IgG antibodies. ${ }^{17}$ The reason for this discrepancy in seropositivity rates between these two populations is unknown, but may be due to higher rates of asymptomatic VZV infections in temperate countries than in tropical countries. To our surprise, $47 \%$ subjects with a past history of chickenpox were sero-negative to anti-VZV IgG antibodies, with a positive past history giving a positive predictive value $(P P V)$ of only 53\%. Although our study found a larger number of those with a past history of chickenpox to be sero-negative to anti-VZV IgG antibodies, it was understandable to some extent when comparing our data with Liyanage et al. (2007) ${ }^{9}$ in that $28 \%$ of those with a self reported history of chickenpox were sero-negative for VZV IgG antibodies giving a PPV of $72 \%$. Thus the basis of using a positive past history of chickenpox to assume sero-positivity to anti-VZV IgG antibodies can be challenged with the data of our study and that of Liyanage et al. $(2007)^{9}$. The 
respondents to a positive history of chickenpox might have had some other exanthematous illness that led to an incorrect assumption of a past history of chickenpox. Apart from this, it is difficult to explain such high sero-negative rates of anti-VZV IgG antibodies in those giving a past history of chickenpox.

Recruits without sibling/s were non immune, those who had 2 siblings and those who had more than 2 siblings had an anti-VZV IgG sero-positivity rate of $27 \%$ and $39 \%$, respectively. The increase in the sero-prevalence rate of anti-VZV IgG antibodies was positively correlated with the increase in the number of siblings. Similar observations have been documented in an adolescent population in Switzerland. ${ }^{18}$ These studies therefore support the fact that those who grow up without siblings have a significant risk of evading natural VZV infection in childhood and hence form a potential target group for adulthood chickenpox.

Students from the urban and estate communities had 53\% and 31\% sero-prevalence rates. Only $17 \%$ of the rural community students were sero-positive to anti-VZV IgG antibodies. The discrepancy in anti-VZV IgG antibody status between urban and rural populations may be due to differences in socio-economic standards, cultural factors and population mobility between these two populations. The estate population has a seropositivity rate of anti-VZV IgG antibodies that lies in between the urban and rural populations. The estate population is more or less similar to a rural population in terms of socio-economic standards and cultural factors. Overcrowded households in close proximity to each other may be the reason for the relatively higher sero-positivity rate in the estate population compared with the rural population where isolated households are more common. In this regard our findings are in agreement with the findings of Liyanage et al. $(2007)^{9}$ in that the urban population of their study had a comparatively higher anti-VZV IgG sero-positivity rate than that of the rural population in a different district (Colombo) of Sri Lanka.

There is no vaccination policy in Sri Lanka for susceptible individuals when they are in high school or prior to starting higher education or other technical training programmes. In that context, our findings are useful to identify the target group for chickenpox immunisation. Those that start higher education in medicine and allied health sciences are especially at risk of acquiring VZV from infected patients during professional training. Other higher educational students might be at risk when they live in university residential colleges or technical training institutes. The infected/diseased can be distracted from their studies, training, examinations and work, contributing to a productivity loss. Moreover, if infected individuals are admitted to hospitals, they could act as a source of infection for immuno-compromised patients and other susceptible risk groups such as pregnant women and the elderly. Medical expenditure for the treatment of chickenpox and its complications can also be high although health economics data are not available in Sri Lanka. Hence, community based studies are necessary at district levels in the country to find out the susceptibility rate of young adults (12-19 years-old) to identify the target population for the immunisation programme in the future. 
In conclusion, sero-prevalence of anti-VZV IgG antibodies is low among adolescents in the Kandy district of Sri Lanka when compared with their counterparts in temperate countries. Individuals who live in urban areas have a significantly higher anti-VZV IgG positivity rate than those who live in rural areas. Adolescents who grow up without siblings are at risk of evading natural VZV infection in childhood and form a target group for adulthood chickenpox and complications.

\section{Conflict of interest}

None declared by the authors.

\section{References}

1 Wallington T, Weir E. "Varicella control and vaccine coverage: issues and challenges. Canadian Medical Association J 2002; 166:631-2. No doi

2 Semenovitch I, Lupi. O. A sero-epidemiologic survey of the prevalence of varicella-zoster virus in the pediatric population in two university hospitals in Brazil. Int J Dermatol 2003; 42:193-6. doi : http://dx.doi.org/10.1046/j.13654362.2003.01310.x

3 Aitken C, Jeffries DJ. Nosocomial spread of viral disease. Clin Microbiol Rev 2001; 14:528-46. doi: http://dx.doi.org/10.1128/CMR.14.3.528-546.2001

4 Ross, LF, Lantos JD. Immunisation against chickenpox. $B M J$ 1995; 310:2-3. doi: http://dx.doi.org/10.1136/bmj.310.6971.2

5 Sauerbrei A, Wutzler P. Different genotype pattern of varicella-zoster virus obtained from patients with varicella and zoster in Germany. J Med Virol 2007; 79:1025-31. doi: http://dx.doi.org/10.1002/jmv.20879

6 Venkitaraman AR, Seigneurin JM, Baccard M, Lenoir GM, John TJ. Measurement of antibodies to varicella-zoster virus in a tropical population by enzyme-linked immunosorbent assay. J Clin Microbiol 1984; 20:582-3. No doi

7 Ooi PL, Goh KT, Doraisingham S, Ling AE. Prevalence of varicella-zoster virus infection in Singapore. Southeast Asian J Trop Med Public Health 1992; 23:22-5. No doi

8 Akram DS, Qureshi H, Mahmud A, Khan AA, Kundi Z, Shafi S et al. Seroepidemiology of varicella-zoster in Pakistan. Southeast Asian J Trop Med Public Health 2000; 31:646-9. No doi

9 Liyanage NP, Fernando F, Malavige GN, Mallikahewa R, Sivayogan S, Jiffry MT et al. Sero-prevalence of varicella zoster virus infections in Colombo district, Sri Lanka. Indian J Med Sci 2007; 61:128-34. doi: http://dx.doi.org/10.4103/0019-5359.30747

10 Uduman SA, Tahira AM, Al-Wash R, Usmani MA, Bener A. Varicella susceptibility among children and healthy adults in the United Arab Emirates. East Mediterr Health J 2001; 7:604-8. No doi

11 Kurukulasooriya GM, Thevanesam V, Agampodi SB, Abeykoon AM, Amarasinghe SP, Goonasekara KP. Susceptibility of new entrant university students in Sri Lanka to varicella zoster infection. Asia Pac J Public Health 2010; 22:219-224. doi: http://dx.doi.org/10.1177/1010539509334625

12 Lawanga SK, Lemeshow S. Sample size determination in health studies. A practical manual World Health Organisation; 1991. accessible at http://whqlibdoc.who.int/publications/9241544058_(p1-p22).pdf 
13 Welgama U, Wickramasinghe C, Perera J. Varicella-zoster virus infection in the Infectious Diseases Hospital, Sri Lanka.Ceylon Med J 2003; 48:119-21. No doi

14 Malavige GN, Jones L, Kamaladasa SD, Wijewickrama A, Seneviratne SL, Black AP et al. Viral load, clinical disease severity and cellular immune responses in primary varicella zoster virus infection in Sri Lanka. PLoS One 2008; 3: e3789. doi: ttp://dx.doi.org/10.1371/journal.pone.0003789

15 O'Grady KA, Merianos A, Patel M, Gilbert L. High sero-prevalence of antibodies to varicella zoster virus in adult women in a tropical climate. Trop Med Int Health 2000; 5:732-6. No doi

16 Lolekha S, Tanthiphabha W, Sornchai P, Kosuwan P, Sutra S, Warachit B et al. Effect of climatic factors and population density on varicella zoster virus epidemiology within a tropical country. Am J Trop Med Hyg 2001; 64:131-6. No doi

17 Boulianne N, Duval B, De Serres G, Deceuninck G, Masse R, Couillard M. Most ten-year-old children with negative or unknown histories of chickenpox are immune. Pediatr Infect Dis J 2001; 20:1087-8. doi: http://dx.doi.org/10.1097/00006454-200111000-00017

18 Heininger U, Braun-Fahrlander C, Desgrandchamps D, Glaus J, Grize L, Wutzler $\mathrm{P}$ et al. Sero-prevalence of varicella-zoster virus immunoglobulin $\mathrm{G}$ antibodies in Swiss adolescents and risk factor analysis for sero-negativity. Pediatr Infect Dis J 2001; 20:775-8. doi: http://dx.doi.org/10.1097/00006454200108000-00011 